\title{
Time to surgery and preoperative cerebral hemodynamics predict postoperative white matter injury in neonates with hypoplastic left heart syndrome
}

\author{
Jennifer M. Lynch, PhD, ${ }^{a}$ Erin M. Buckley, PhD,,${ }^{\mathrm{a}, \mathrm{b}, \mathrm{c}}$ Peter J. Schwab, BS, ${ }^{c}$ Ann L. McCarthy, BBA, ${ }^{c}$ \\ Madeline E. Winters, BA, ${ }^{\mathrm{c}}$ David R. Busch, PhD, ${ }^{\mathrm{c}}$ Rui Xiao, PhD, ${ }^{\mathrm{d}}$ Donna A. Goff, MD, MS, \\ Susan C. Nicolson, MD, ${ }^{f}$ Lisa M. Montenegro, MD,${ }^{f}$ Stephanie Fuller, MD, ${ }^{g}$ J. William Gaynor, MD, ${ }^{g}$ \\ Thomas L. Spray, MD, ${ }^{\mathrm{g}}$ Arjun G. Yodh, PhD, ${ }^{\mathrm{a}}$ Maryam Y. Naim, MD, ${ }^{\mathrm{h}}$ and Daniel J. Licht, MD
}

Objective: Hypoxic-ischemic white mater brain injury commonly occurs in neonates with hypoplastic left heart syndrome (HLHS). Approximately one half of HLHS survivors will exhibit neurobehavioral symptoms believed to be associated with this injury, although the exact timing of the injury is unknown.

Methods: Neonates with HLHS were recruited for pre- and postoperative monitoring of cerebral oxygen satu-
ration, cerebral oxygen extraction fraction, and cerebral blood flow using 2 noninvasive optical-based tech-
niques: diffuse optical spectroscopy and diffuse correlation spectroscopy. Anatomic magnetic resonance
imaging was performed before and approximately 1 week after surgery to quantify the extent and timing of
the acquired white matter injury. The risk factors for developing new or worsened white matter injury were as-
sessed using uni- and multivariate logistic regression.

Results: A total of 37 neonates with HLHS were studied. On univariate analysis, neonates who developed a large volume of new, or worsened, postoperative white matter injury had a significantly longer time to surgery $(P=.0003)$. In a multivariate model, a longer time between birth and surgery, delayed sternal closure, and greater preoperative cerebral blood flow were predictors of postoperative white matter injury. Additionally, a longer time to surgery and greater preoperative cerebral blood flow on the morning of surgery correlated with lower cerebral oxygen saturation $(P=.03$ and $P=.05$, respectively) and greater oxygen extraction fraction $(P=.05$ for both).

Conclusions: A longer time to surgery was associated with new postoperative white matter injury in otherwise healthy neonates with HLHS. The results suggest that earlier Norwood palliation might decrease the likelihood of acquiring postoperative white matter injury. (J Thorac Cardiovasc Surg 2014;148:2181-8)

See related commentary on pages $2188-9$.

Approximately 30,000 children annually are born in the United States with congenital heart disease (CHD). Nearly

\footnotetext{
From the Department of Physics and Astronomy, ${ }^{a}$ University of Pennsylvania, Philadelphia, Pa; Athinoula A. Martinos Center for Biomedical Imaging, ${ }^{\mathrm{b}}$ Optics Division, Massachusetts General Hospital, Charlestown, Mass; Division of Neurology, ${ }^{\mathrm{c}}$ The Children's Hospital of Philadelphia, Philadelphia, Pa; Department of Biostatistics and Epidemiology, ${ }^{\mathrm{d}}$ University of Pennsylvania, Philadelphia, Pa; Division of Pediatric Cardiology, ${ }^{\mathrm{e}}$ Loma Linda University Children's Hospital, Loma Linda, Calif; Division of Cardiothoracic Anesthesia, ${ }^{f}$ The Children's Hospital of Philadelphia, Philadelphia, Pa; Division of Cardiothoracic Surgery, ${ }^{\mathrm{g}}$ The Children's Hospital of Philadelphia, Philadelphia, Pa; and Division of Critical Care Medicine, ${ }^{\text {h }}$ The Hospital of Philadelphia, Philadelphia, Pa.

This study was supported by the National Institutes of Health (grants NS-072338, NS-60653, HL-007954, HL-007915, and P41-EB015893), the Thrasher Research Foundation, and the June and Steve Wolfson Family foundation.

Disclosures: Authors have nothing to disclose with regard to commercial support.

Received for publication Feb 27, 2014; revisions received May 12, 2014; accepted for publication May 29, 2014; available ahead of print Aug 7, 2014.

Address for reprints: Jennifer M. Lynch, PhD, Department of Physics and Astronomy,

University of Pennsylvania, 209 South 33rd St, Philadelphia, PA 19104 (E-mail: jenlynch@alumni.upenn.edu).

$0022-5223 / \$ 36.00$

Copyright (C) 2014 by The American Association for Thoracic Surgery

http://dx.doi.org/10.1016/j.jtcvs.2014.05.081
}

one third of these patients with CHD require cardiac surgery in their first year of life. ${ }^{1}$ With most of these patients now reaching school age, ${ }^{2}$ the focus of research has shifted to addressing the neurodevelopment disabilities seen among survivors of these early heart surgeries. Nearly $50 \%$ of the school-age survivors exhibit neurobehavioral symptoms, such as inattention, hyperactivity, and impaired executive function. ${ }^{3-5}$

Neonatal imaging and neuropathologic studies of patients with complex CHD undergoing infant surgical intervention have revealed a high prevalence of periventricular leukomalacia (PVL). ${ }^{6}$ PVL is a specific form of hypoxicischemic white matter injury that commonly occurs in a vascular watershed zone near the lateral ventricles. It is most often observed in preterm neonates, who have had neurodevelopmental outcomes remarkably similar to those of term patients with CHD. Studies have shown that PVL is related to neurodevelopmental delays in preterm infants. ${ }^{7-9}$

To date, clinical investigations of CHD neonates have focused on identifying the pre-, peri-, and postoperative risk factors linked to PVL to mitigate or prevent this injury. ${ }^{10-12}$ However, uncertainties about its exact cause and timing remain. ${ }^{10-12}$ These previous studies have 


$$
\begin{aligned}
& \text { Abbreviations and Acronyms } \\
& \begin{aligned}
\mathrm{BFI} & =\text { blood flow index } \\
\mathrm{CBF} & =\text { cerebral blood flow } \\
\mathrm{CHD} & =\text { congenital heart disease } \\
\mathrm{CICU} & =\text { cardiac intensive care unit } \\
\mathrm{CMRO} & =\text { cerebral metabolic rate of oxygen } \\
\mathrm{DCS} & =\text { diffuse correlation spectroscopy } \\
\mathrm{DHCA} & =\text { deep hypothermic circulatory arrest } \\
\mathrm{DOS} & =\text { diffuse optical spectroscopy } \\
{[\mathrm{Hb}] } & =\text { deoxyhemoglobin } \\
{[\mathrm{HbO}} & =\text { oxyhemoglobin } \\
\mathrm{HLHS} & =\text { hypoplastic left heart syndrome } \\
\mathrm{MRI} & =\text { magnetic resonance imaging } \\
\mathrm{OEF} & =\text { cerebral oxygen extraction fraction } \\
\mathrm{PVL} & =\text { periventricular leukomalacia } \\
\mathrm{ScO} & =\text { cerebral tissue oxygen saturation } \\
\mathrm{THC} & =\text { total hemoglobin concentration } \\
\mathrm{TMS} & =\text { total maturation score }
\end{aligned}
\end{aligned}
$$

identified possible risk factors for this injury such as brain immaturity, the duration of deep hypothermic circulatory arrest (DHCA), and postoperative cerebral oxy-genation. ${ }^{12-14}$ However, most previous studies have been of mixed populations of neonates with various forms of CHD. We investigated a homogeneous cohort of neonates with hypoplastic left heart syndrome (HLHS). We used diffuse optical and diffuse correlation spectroscopy (DOS and DCS, respectively) for noninvasive bedside quantification of the pre- and postoperative cerebral hemodynamics. ${ }^{15,16}$ Also, we explored the relationship of these parameters and other preoperative, operative, and postoperative variables with new or worsened PVL seen 1 week after surgical intervention.

\section{METHODS \\ Patient Population}

All term (37-42 weeks' gestation) newborns with pre- or postnatally diagnosed HLHS who had been admitted to the cardiac intensive care unit (CICU) at The Children's Hospital of Philadelphia were screened for study inclusion and approached for participation in the present prospective study. The exclusion criteria included birth weight $<2 \mathrm{~kg}$, a history of neonatal depression (ie, 5-minute APGAR of $<5$ or cord $\mathrm{pH}$ of $<7.0$ ), perinatal seizures, evidence of end-organ injury, preoperative cardiac arrest, and/or significant preoperative intracerebral hemorrhage such as grade 3 or 4 intraventricular hemorrhage.

\section{Study Protocol}

The institutional review board approved all procedures. The patients' demographic data were recorded. A study timeline is presented in Figure 1 and has been described previously. ${ }^{17-20}$ On the morning of surgery, all patients received general endotracheal anesthesia (fentanyl 5-10 $\mu \mathrm{g} / \mathrm{kg}$, pancuronium $0.2 \mathrm{mg} / \mathrm{kg}$ ). Subsequently, they underwent brain magnetic resonance imaging (MRI) for preoperative injury assessment. Preoperative
DOS and DCS measurements of cerebral oxygenation $\left(\mathrm{ScO}_{2}\right)$, oxygen extraction (OEF), and cerebral blood flow (CBF) were also taken at this time.

After MRI, the patients underwent cardiopulmonary bypass with DHCA for their stage I palliation. Antegrade cerebral perfusion was not used. The operations were performed by 1 of 4 cardiac surgeons. pH-stat blood gas management was used. To achieve DHCA, the patients underwent core and surface cooling to a nasopharyngeal temperature of $18^{\circ} \mathrm{C}$. Commercial cerebral oximetry was not used to guide intra- or postoperative management. Patients received either a Blalock-Taussig shunt or a right ventricle to pulmonary artery shunt (Sano). The surgical strategy included sternal closure where tolerated. Patients born with an intact atrial septum underwent balloon atrial septostomy soon after birth and before surgery.

After surgery, the patients were transported back to the CICU. The postoperative $\mathrm{ScO}_{2}, \mathrm{OEF}$, and CBF were quantified every 2 hours for the first 12 hours during recovery. Approximately 1 week after surgery, the patients underwent a postoperative follow-up MRI scan to assess the development and/or progression of brain injury.

\section{Brain MRI}

All images were acquired using a 1.5T Avanto MRI system (Siemens Medical Systems, Malvern, Pa) using a 12-channel head coil. The studies included $\mathrm{T}_{1}$-weighted magnetization-prepared rapid acquisition gradient echo and $\mathrm{T}_{2}$-weighted sampling perfection with application-optimized contrasts using different flip angle evolution sequences acquired in the axial plane. The images were later reconstructed in the sagittal and coronal planes. Susceptibility and diffusion weighted sequences were also acquired. The presence of PVL was assessed from the $T_{1}$-weighted sequences in conjunction with diffusion weighted imaging on both the pre- and postoperative scans. Manual segmentation of the $\mathrm{T}_{1}$-weighted hyperintense lesions was performed using ITK-SNAP ${ }^{21}$ (available at: http://www.itksnap. org/) and used to calculate the PVL volumes. New or worsened PVL was calculated by the difference in the PVL volume between the post- and preoperative scans. Additionally, 2 independent observers, who were unaware of the clinical data, evaluated the total brain maturation score (TMS) using axial $\mathrm{T}_{1^{-}}$and $\mathrm{T}_{2}$-weighted images. ${ }^{22,23}$

\section{DOS and DCS Measurements}

DOS and DCS use near-infrared light to noninvasively probe the static and dynamic properties of cortical brain tissue. Our custom-made optical instrument combines these 2 techniques on a mobile cart that can be used in the MRI suite and operating room and at the bedside during recovery. ${ }^{17,18,24}$

DOS (also known as near-infrared spectroscopy) is a widely accepted method for quantifying tissue oxygenation. Multiseparation frequency domain DOS, used in the present study, is capable of accurate quantification of $\mathrm{ScO}_{2}$ (ie, in contrast to commercial oximeters, which use continuouswave near-infrared spectroscopy to monitor trends in saturation). DOS uses the photon diffusion theory to relate the measured amplitude attenuation and phase shift of modulated and multiply scattered light detected on the tissue surface to the wavelength-dependent tissue absorption $\left(\mu_{a}\right)$ and scattering $\left(\mu_{s}^{\prime}\right)$ properties. The wavelength- and time-dependent absorption coefficient, $\mu_{a}(\lambda, t)$, depends linearly on the oxy- $\left(\left[\mathrm{HbO}_{2}\right]\right)$ and deoxyhemoglobin $([\mathrm{Hb}])$ concentration; thus measurements at multiple wavelengths yields these 2 parameters. From $\left[\mathrm{HbO}_{2}\right]$ and $[\mathrm{Hb}]$, we can derive the total hemoglobin concentration (THC) $\left(\mathrm{THC}=\left[\mathrm{HbO}_{2}\right]+[\mathrm{Hb}]\right)$ and $\mathrm{ScO}_{2}\left(\mathrm{ScO}_{2}=\left[\mathrm{HbO}_{2}\right] / \mathrm{THC}\right)$. The OEF can be calculated from the $\mathrm{ScO}_{2}$ and arterial oxygen saturation measured clinically from an arterial blood gas sample. ${ }^{17}$ The cerebral blood volume ( $\mathrm{mL} / 100 \mathrm{~g}$ of tissue) can be calculated from the THC. ${ }^{25}$ The DOS device used in the present study (Imagent, ISS Inc, Champaign, Ill) is amplitude modulated at $110 \mathrm{MHz}$ and uses source lasers at 2 wavelengths, $\lambda=688$ and $830 \mathrm{~nm}$.

DCS uses near-infrared light to noninvasively monitor the CBF. DCS measures the temporal fluctuations of the reflected light intensity at the tissue surface, which are primarily caused by moving red blood cells. ${ }^{15,26,27}$ 


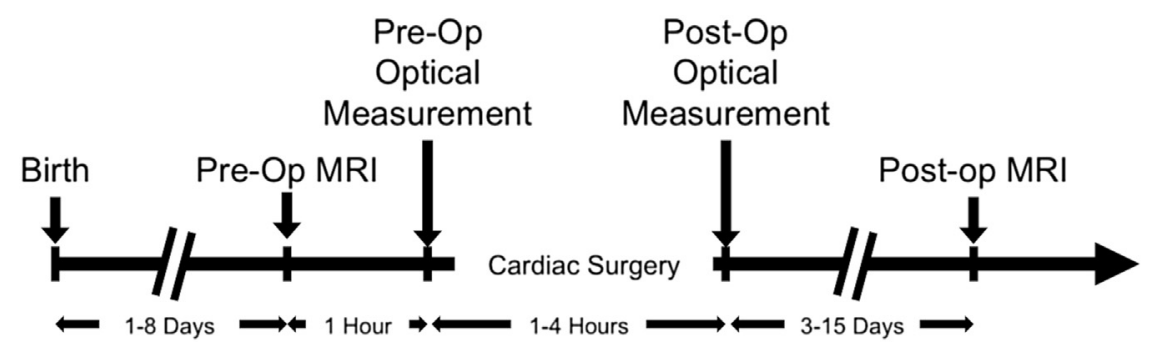

FIGURE 1. Timeline of the study. Pre-Op, Preoperative; Post-Op, postoperative; MRI, magnetic resonance imaging.

The correlation diffusion theory is used to convert these temporal fluctuations to a blood flow index (BFI, measured in units of $\mathrm{cm}^{2} / \mathrm{s}$ ). ${ }^{15}$ Although this index does not have the traditional physiologic units of $\mathrm{CBF}$, recent studies have shown that the BFI correlates strongly with other reference standard measures of $\mathrm{CBF}^{18,28}$ Specifically, Jain and colleagues $^{18}$ validated the BFI against the $\mathrm{CBF}$ measured in the superior sagittal sinus with phase contrast MRI in a similar population of infants with critical CHD. ${ }^{18}$ Furthermore, the BFI can be combined with DOSmeasured $\mathrm{ScO}_{2}$ and clinical arterial oxygenation measured clinically from arterial blood samples to give an index of the cerebral metabolic rate of oxygen consumption $\left(\mathrm{CMRO}_{2}\right){ }^{17,24}$

DOS and DCS measurements were conducted once preoperatively, once postoperatively immediately after the return to the CICU, and once every 2 hours for the next 12 hours. For statistical analysis of the postoperative measurements, we included only the initial value of $\mathrm{ScO}_{2}$ and $\mathrm{BFI}$ on return to the $\mathrm{CICU}$ and the lowest measured postoperative $\mathrm{ScO}_{2}$ value. The measurements were made over the right and left frontal cortex. At each location, 4 repetitions were acquired to account for local inhomogeneities under the optical probe. These 8 repetitions were then averaged to derive a global measure of the $\mathrm{ScO}_{2}$ and BFI. The optical data measured using DOS and DCS (ie, $\mathrm{ScO}_{2}$ and $\mathrm{BFI}$ ) were acquired for only a subset of patients owing to a change in the protocol that included improved optical instrumentation and allowed for these optical measurements partway through enrollment.

\section{Statistical Analysis}

Continuous variables were summarized using standard descriptive statistics (mean \pm standard deviation and median and interquartile range, as appropriate) and frequencies and percentages for categorical variables. Because of the highly skewed distribution of PVL volumes in the present data set, the outcome variable of new or worsened postoperative PVL was dichotomized around its median value.

To test for risk factors for new or worsened PVL, univariate analysis was performed using Wilcoxon rank sum tests to compare the median of each explanatory variable between the group with a large PVL volume and the group with a small PVL volume or no PVL. Furthermore, multivariate logistic regression was performed to evaluate the significance of the explanatory variables to predict the likelihood of developing a large amount (ie, greater than the median value) of new or worsened postoperative PVL. The final selected model was determined by stepwise selection, which is a combination of backward elimination and forward selection. In stepwise selection, an attempt is made to remove any insignificant variables from the model before adding a significant variable to the model. Each addition or deletion of a variable to or from the model is a separate step, and at each step, a new model is fitted. The selection criteria was $P<.1$. All variables tested on univariate analysis were included for consideration in the stepwise selection approach.

\section{RESULTS}

From October 2008 to March 2013, a total of 41 neonates were recruited for the present study; however, postoperative
MRI scans were not acquired for 4 patients: 2 patients were deemed clinically unstable for postoperative MRI during study period, 1 subject had had a pacemaker placed and was thus unable to undergo MRI, and 1 subject was withdrawn from postoperative MRI by parental request. Thus, 37 neonates diagnosed with HLHS $(\mathrm{n}=30)$ or an HLHS variant $(\mathrm{n}=7)$ were included in the present analysis because they had both pre- and postoperative MRI available. The HLHS variants consisted of unbalanced atrioventricular canal in 4 , double outlet right ventricle in 2 , and mitral valve dysplasia and aortic valve stenosis in 1; all had associated aortic arch hypoplasia. All patients were full term with an average gestational age of $38.9 \pm 0.8$ weeks, and all but 1 patient had been diagnosed prenatally. The patient demographics and pre- and postoperative cerebral hemodynamics are listed in Table 1. A subset of this patient population has been previously described. ${ }^{18,29}$

The preoperative $\mathrm{BFI}$ and $\mathrm{ScO}_{2}$ were acquired in 29 of the 37 patients. The postoperative BFI was acquired in 29 of the 37 and the postoperative $\mathrm{ScO}_{2}$ in 28 of the 37 subjects owing to a change in protocol that used improved optical instrumentation.

Eight patients (21.6\%) had preoperative and $28(75.7 \%)$ had postoperative PVL. An increase in PVL volume from pre- to postoperatively was observed in 26 of the 37 patients $(70.3 \%)$, and the acquired volume ranged from 2.5 to $7577.7 \mathrm{~mm}^{3}$. A highly skewed distribution of PVL volumes existed in this cohort (mean, $573.4 \mathrm{~mm}^{3}$; median, $76.3 \mathrm{~mm}^{3}$; skewness $=3.7$ ). Therefore, the volumes were dichotomized around the median value to yield "none or small" volumes and "large" volumes (more clinically significant). Thus, large volumes of new or worsened postoperative PVL occurred in $48.7 \%$. Figure 2 illustrates an example of a large volume $\left(7577.7 \mathrm{~mm}^{3}\right)$ versus a small volume $(70.7$ $\mathrm{mm}^{3}$ ) of PVL. Table 1 gives the pre- and postoperative and demographic data for those subjects with a large change in the postoperative PVL and those without or with a small amount. The group with a large amount of postoperative of PVL had had a mean time to surgery of $5.3 \pm 1.5$ days compared with $3.1 \pm 1.7$ days for the no or small PVL amount group $(P=.0003)$.

No clinical indications were identified that resulted in delay in surgery in the group with a large amount of new 
TABLE 1. Summary of demographic and pre- and postoperative cerebral hemodynamic variables for subjects with and without new or worsened PVL $>76.3 \mathrm{~mm}^{3}$

\begin{tabular}{|c|c|c|c|c|}
\hline Variable & All $(\mathbf{n}=37)$ & PVL $(n=18)$ & No PVL $(n=19)$ & $P$ value \\
\hline Time to surgery (d) & $4.2 \pm 1.9$ & $5.3 \pm 1.5$ & $3.1 \pm 1.7$ & $<.001 *$ \\
\hline Time between MRI (d) & $7.1 \pm 2.8$ & $7.1 \pm 2.9$ & $7.0 \pm 2.9$ & .90 \\
\hline Gestational age (wk) & $38.8 \pm 0.8$ & $38.9 \pm 0.9$ & $38.8 \pm 0.7$ & .59 \\
\hline Birth weight $(\mathrm{kg})$ & $3.3 \pm 0.5$ & $3.3 \pm 0.5$ & $3.2 \pm 0.5$ & .77 \\
\hline Head circumference $(\mathrm{cm})$ & $34.0 \pm 1.4$ & $34.1 \pm 1.5$ & $34.0 \pm 1.3$ & .55 \\
\hline Female sex & $19(51.4)$ & $10(55.6)$ & $9(47.4)$ & .64 \\
\hline Aortic stenosis & $9(27.3)$ & $5(31.3)$ & $4(23.5)$ & .64 \\
\hline Blalock-Taussig shunt & $28(75.7)$ & $13(72.2)$ & $15(79.0)$ & .65 \\
\hline Intact atrial septum & $4(10.8)$ & $1(5.6)$ & $3(15.8)$ & .34 \\
\hline TMS & $9.9 \pm 0.9$ & $10.1 \pm 0.9$ & $9.8 \pm 1.0$ & .34 \\
\hline Preoperative $\mathrm{SaO}_{2}(\%)$ & $90.0 \pm 5.2$ & $90.1 \pm 4.0$ & $89.9 \pm 6.1$ & .57 \\
\hline \multicolumn{5}{|l|}{ Preoperative cerebral hemodynamics } \\
\hline $\mathrm{ScO}_{2}(\%)$ & $48.8 \pm 13.3$ & $44.3 \pm 13.4$ & $54.3 \pm 11.3$ & $.09 \dagger$ \\
\hline BFI $\left(10^{-8} \mathrm{~cm}^{2} / \mathrm{s}\right)$ & $2.4 \pm 1.6$ & $3.0 \pm 1.9$ & $1.9 \pm 1.1$ & $.05 \dagger$ \\
\hline $\mathrm{CBV}(\mathrm{mL} / 100 \mathrm{~g})$ & $2.1 \pm 0.5$ & $2.1 \pm 0.6$ & $2.1 \pm 0.4$ & .52 \\
\hline $\mathrm{OEF}$ & $0.61 \pm 0.20$ & $0.68 \pm 0.22$ & $0.54 \pm 0.16$ & .15 \\
\hline $\mathrm{CMRO}_{2, \mathrm{i}}\left(10^{-7} \mathrm{~mL} / \mathrm{dL} \times \mathrm{cm}^{2} / \mathrm{s}\right)$ & $1.7 \pm 1.4$ & $2.1 \pm 1.9$ & $1.4 \pm 0.6$ & .26 \\
\hline \multicolumn{5}{|l|}{ Operative variables } \\
\hline CPB time (min) & $92.2 \pm 25.3$ & $96.8 \pm 33.0$ & $87.7 \pm 14.5$ & .70 \\
\hline DHCA time (min) & $44.8 \pm 9.7$ & $46.4 \pm 12.0$ & $43.3 \pm 6.7$ & .74 \\
\hline Lowest NP temperature & $17.8 \pm 0.9$ & $17.9 \pm 1.0$ & $17.6 \pm 0.8$ & .20 \\
\hline Bypass runs (n) & $1.1 \pm 0.4$ & $1.2 \pm 0.5$ & $1.0 \pm 0$ & .14 \\
\hline Delayed sternal closure & $5(13.5)$ & $4(22.2)$ & $1(5.3)$ & .14 \\
\hline Cardiac arrest before postoperative MRI & $2(5.4)$ & $2(11.1)$ & $0(0)$ & .15 \\
\hline \multicolumn{5}{|l|}{ Postoperative cerebral hemodynamics } \\
\hline Initial $\mathrm{ScO}_{2}(\%)$ & $40.8 \pm 7.2$ & $41.3 \pm 7.6$ & $40.4 \pm 7.1$ & .57 \\
\hline Initial BFI $\left(10^{-8} \mathrm{~cm}^{2} / \mathrm{s}\right)$ & $1.5 \pm 0.7$ & $1.6 \pm 0.9$ & $1.3 \pm 0.3$ & .35 \\
\hline Initial CBV (mL/100 g) & $3.9 \pm 0.7$ & $3.9 \pm 0.7$ & $3.8 \pm 0.8$ & .83 \\
\hline Initial OEF & $0.58 \pm 0.15$ & $0.57 \pm 0.14$ & $0.59 \pm 0.16$ & .85 \\
\hline Initial $\mathrm{CMRO}_{2, \mathrm{i}}\left(10^{-7} \mathrm{~mL} / \mathrm{dL} \times \mathrm{cm}^{2} / \mathrm{s}\right)$ & $1.9 \pm 1.8$ & $2.0 \pm 1.4$ & $1.7 \pm 2.2$ & .24 \\
\hline Lowest $\mathrm{ScO}_{2}(\%)$ & $35.0 \pm 9.4$ & $34.2 \pm 10.5$ & $35.9 \pm 8.3$ & .65 \\
\hline \multicolumn{5}{|l|}{ Change from pre- to postoperatively } \\
\hline $\mathrm{ScO}_{2, \text { postoperative }}-\mathrm{ScO}_{2, \text { preoperative }}(\%)$ & $-8.0(13.1)$ & $-3.9(12.5)$ & $-12.4(12.8)$ & .10 \\
\hline $\mathrm{BFI}_{\text {postoperative }} / \mathrm{BFI}_{\text {preoperative }}(\%)$ & $1.1(0.5)$ & $1.1(0.6)$ & $1.0(0.4)$ & .68 \\
\hline
\end{tabular}

Data presented as mean \pm standard deviation for continuous variables and $\mathrm{n}(\%)$ for categorical variables. A Wilcoxon rank sum test was used to test for differences between the 2 groups. $P V L$, Periventricular leukomalacia; $M R I$, magnetic resonance imaging; $T M S$, total maturation score; $\mathrm{SaO}_{2}$, arterial oxygen saturation; $\mathrm{ScO}_{2}$, cerebral tissue oxygen saturation; $B F I$, blood flow index; $C B V$, cerebral blood volume; $O E F$, cerebral oxygen extraction fraction; $C M R O_{2, i}$, index of cerebral metabolic rate of oxygen; $C P B$, cardiopulmo-

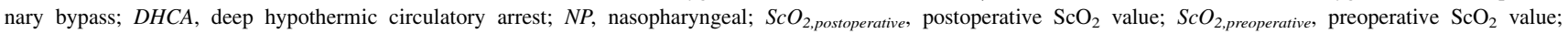
$B F I_{\text {postoperative }}$, postoperative BFI; $B F I_{\text {preoperative }}$, preoperative BFI. *Statistically significant. $\nmid$ Marginally significant.

or worsened PVL. The delays had resulted from scheduling or the availability of the requested surgeon. The day of the week of the infants' birth also played a large role in the time to surgery. For instance, the 7 infants born on a Wednesday had an average time to surgery of $5.1 \pm 1.6$ days, but the 10 infants born on a Monday had an average time to surgery of $3.7 \pm 2.2$ days.

To further illustrate the relationship between the time to surgery and the likelihood of acquired PVL, Figure 3 shows a box plot of volume of new or worsened postoperative PVL for those patients with an time to surgery of $\leq 4$ days and those with an time to surgery of $\geq 5$ days $(P=.0005)$. The cutoff of 4 days was chosen for this visualization, because it resulted in the most significant difference in the volume of acquired PVL between the groups born before and after the cutoff. However, a cutoff of 3 or 5 days also resulted in a significant difference in the volume of acquired PVL $(P=.005$ and $P=.02$, respectively). Although TMS was included in both the univariate and the multivariate analysis, it was not a significant predictor of new or worsened postoperative PVL.

Patients with new or worsened postoperative PVL tended to have a greater preoperative BFI $(P=.05)$ and lower preoperative $\mathrm{ScO}_{2}(P=.09)$. The TMS, postoperative $\mathrm{ScO}_{2}$, and DHCA duration were not significantly different between the 2 groups.

A multivariate logistic regression model resulting from stepwise selection revealed that the probability of acquiring 

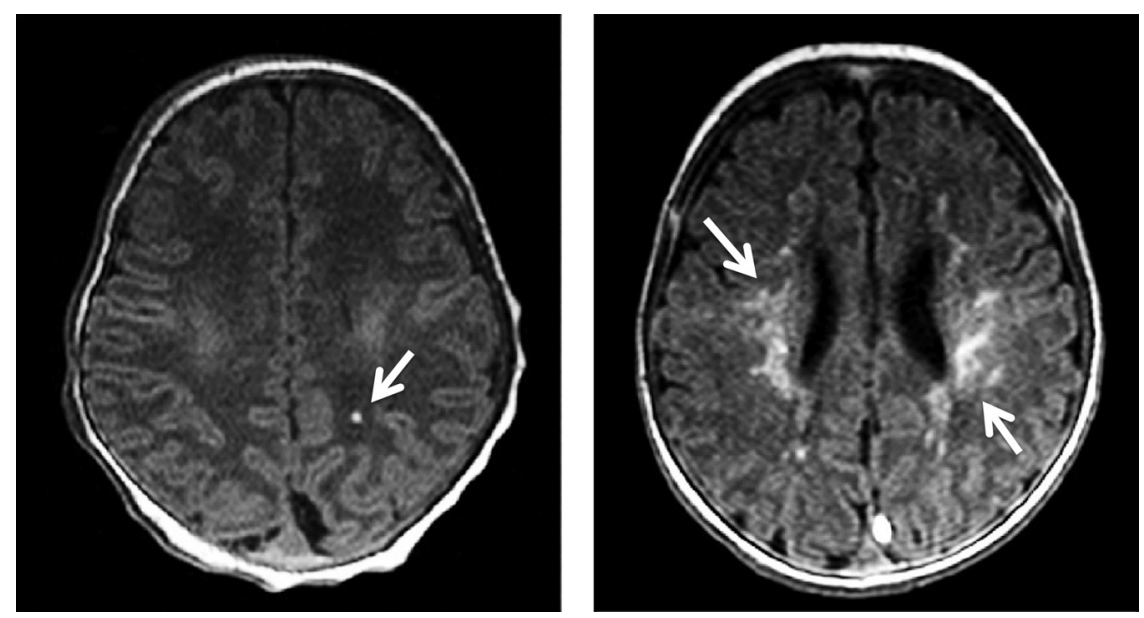

FIGURE 2. An example of a small volume (left, $70.7 \mathrm{~mm}^{3}$; arrow) and a large volume (right, $7577.7 \mathrm{~mm}^{3}$; arrows) periventricular leukomalacia.

a large amount of PVL was positively associated with the time to surgery $(P=.005)$, delayed sternal closure $(P=.07)$, and preoperative BFI $(P=.08)$.

Additionally, we investigated the cross-sectional relationship between the preoperative $\mathrm{ScO}_{2}$ and the time to surgery and between the preoperative $\mathrm{ScO}_{2}$ and preoperative BFI. As seen in Figure 4, a significant and negative linear correlation $\left(\mathrm{R}^{2}=0.17, P=.03\right.$, slope $=-2.7 \pm$ 1.2) was observed between the time to surgery and preoperative $\mathrm{ScO}_{2}$. Also, a significant and negative linear correlation $\left(\mathrm{R}^{2}=0.15, P=.05\right.$, slope $\left.=-3.0 \pm 1.4\right)$ was observed between the preoperative $\mathrm{ScO}_{2}$ and preoperative BFI. We also examined the relationship of preoperative OEF with the time to surgery and preoperative BFI (Figure 4). We observed a significant and positive linear correlation $\left(\mathrm{R}^{2}=0.15, P=.05\right.$, slope $\left.=0.02 \pm 0.01\right)$ between the preoperative $\mathrm{OEF}$ and time to surgery and a

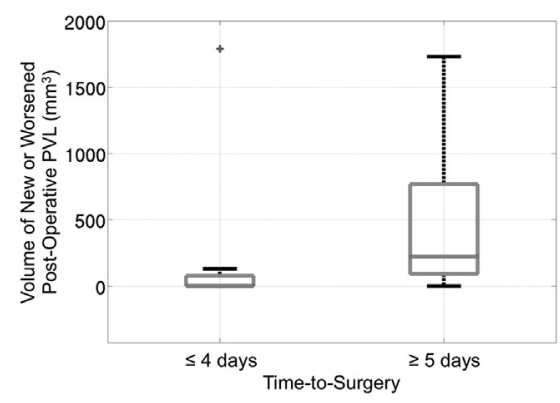

FIGURE 3. Box plot demonstrating the significant $(P=.0005)$ difference in volume of new or worsened postoperative periventricular leukomalacia $(P V L)$ for those patients with a time to surgery of $\leq 4$ days versus $\geq 5$ days. Two outliers were removed to improve the visualization. One outlier was in the left group and had a PVL volume of $7577.7 \mathrm{~mm}^{3}$, and the other outlier was in the right group and had a PVL volume of $4981.5 \mathrm{~mm}^{3}$. These outliers were only removed from Figure 3 but not from the statistical analysis. significant and positive linear correlation $\left(\mathrm{R}^{2}=0.16\right.$, $P=.05$, slope $=0.03 \pm 0.01$ ) between the preoperative $\mathrm{OEF}$ and preoperative $\mathrm{BFI}$.

\section{DISCUSSION}

The major new finding from the present study was that acquired postoperative PVL in infants with HLHS correlated highly $(P=.0003)$ with longer time between birth and palliative infant heart surgery. However, the peri- and postoperative variables did not predict injury. One possible explanation for the significance of the time to surgery on the development of postoperative PVL is derived from the negative linear trend observed between the preoperative $\mathrm{ScO}_{2}$ and the time to surgery (Figure 4), suggesting that cerebral desaturation progresses from birth until surgery. The correlation of the preoperative $\mathrm{ScO}_{2}$ with new or worsened postoperative $\mathrm{PVL}$ and time to surgery suggests that preoperative noninvasive optical monitoring of $\mathrm{ScO}_{2}$ could be useful in further understanding the timing and cause of PVL and has the potential to further decrease the risk of injury.

The finding that a greater preoperative $\mathrm{BFI}$ is associated with new or worsened postoperative PVL on both univariate and multivariate analysis was surprising and is currently under further investigation. As seen in Figure 4, a greater preoperative BFI was associated with a lower preoperative $\mathrm{ScO}_{2}$. This trend possibly resulted from an increasing need for oxygen delivery to meet the greater metabolic demand. Although this parameter has not been measured in healthy newborn infants, it is likely that $\mathrm{CMRO}_{2}$ increases as infants emerge from the dark, quiet, and warm uterine environment into the bright and chaotic world. In infants with severe forms of $\mathrm{CHD}$, this increased oxygen demand might not be well matched with the poor and possibly decreasing cerebral oxygen delivery. This idea is supported by the observed correlation between the greater 

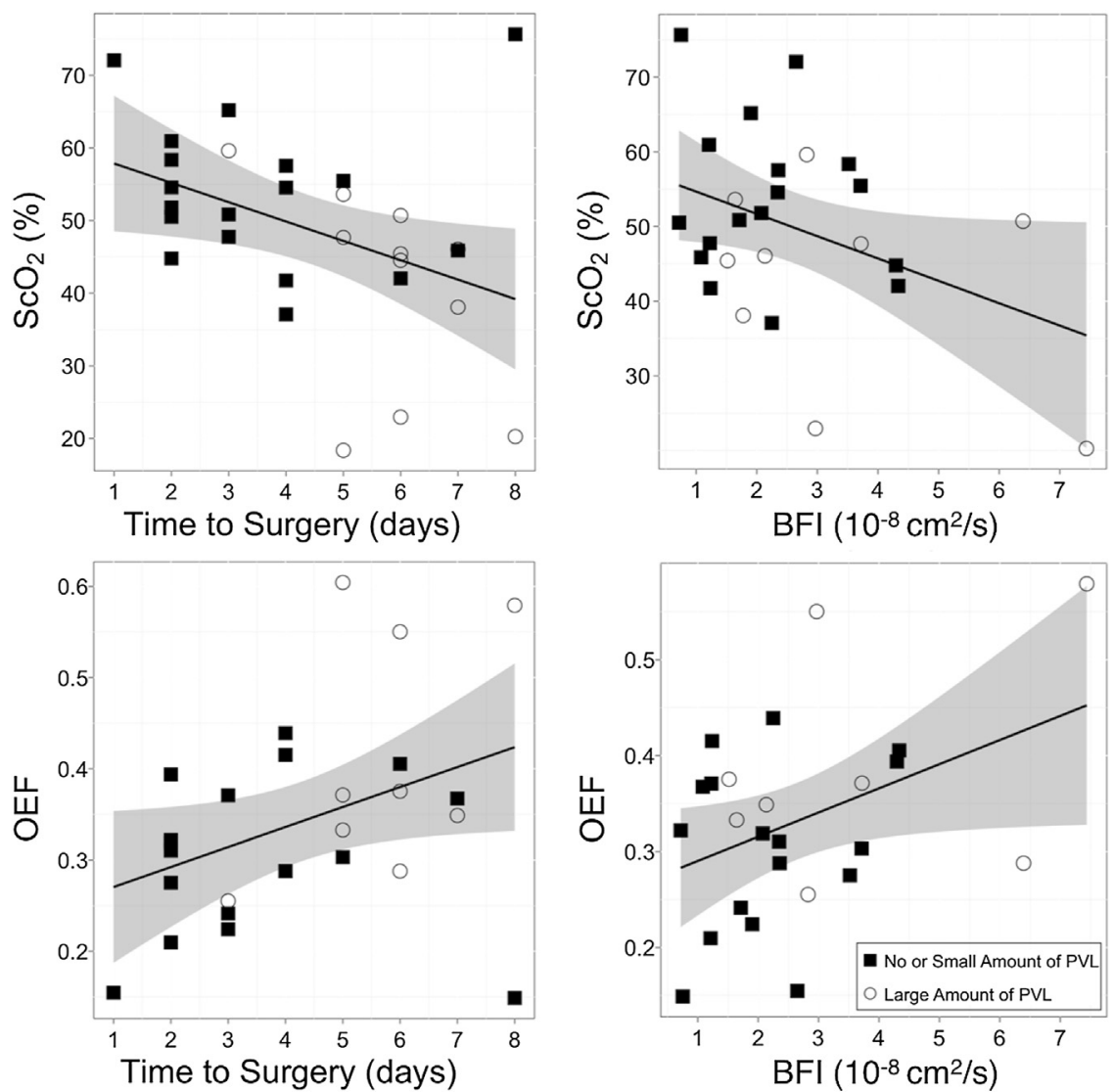

FIGURE 4. Preoperative cerebral oxygenation as a function of the top left, time to surgery and top right, preoperative blood flow index (BFI). Preoperative oxygen extraction fraction as a function of the bottom left, time to surgery and bottom right, preoperative BFI. The solid line represents the best-fit line to the data (top left, $\mathrm{R}^{2}=0.17, P=.03$, slope $=-2.7 \pm 1.2 ;$ top right, $\mathrm{R}^{2}=0.15, P=.05$, slope $=-3.0 \pm 1.4 ;$ bottom left $, \mathrm{R}^{2}=0.15, P=.05$, slope $=0.02 \pm 0.01 ;$ bottom right, $\mathrm{R}^{2}=0.16, P=.05$, slope $=0.03 \pm 0.01$ ). The gray ribbon denotes the $95 \%$ confidence interval for the mean cerebral tissue oxygen saturation $\left(\mathrm{ScO}_{2}\right)$ or cerebral oxygen extraction fraction $(O E F)$. The symbols represent whether the subject had acquired a large amount of new or worsened postoperative periventricular leukomalacia.

preoperative OEF and BFI (Figure 4), thus suggesting that the brain is operating on the supply-dependent portion of the oxygen consumption/delivery curve. ${ }^{30}$ Additional investigation, including serial measurements of $\mathrm{CBF}$, $\mathrm{ScO}_{2}$, OEF, and $\mathrm{CMRO}_{2}$, from birth to surgery on individual patients with and without severe $\mathrm{CHD}$ is crucial for understanding the role of CBF in injury risk.

We also investigated postoperative $\mathrm{ScO}_{2}$ as a risk factor for new or worsened postoperative PVL; however, we did not find a significant difference between groups in either the initial $\mathrm{ScO}_{2}$ on return to the CICU or the lowest $\mathrm{ScO}_{2}$ during the first 12 hours of postoperative recovery. Dent and colleagues ${ }^{14}$ reported that a postoperative $\mathrm{ScO}_{2}$ of $<45 \%$ for $\geq 180$ minutes was significantly associated with postoperative PVL in infants with HLHS. However, in the study by Dent and colleagues, ${ }^{14}$ continuous monitoring of $\mathrm{ScO}_{2}$ was used. In contrast, the $\mathrm{ScO}_{2}$ in the present study was only measured once every 2 hours for the first 12 hours postoperatively. Additionally, this finding by Dent and colleagues ${ }^{14}$ was not replicated later in a mixed population studied by Andropoulus and colleagues. ${ }^{12}$

The total duration of DHCA has been previously investigated as a risk factor for the development of new postoperative PVL in a heterogeneous population with multiple forms of CHD. ${ }^{13}$ In the present study, however, the DHCA duration was not associated with PVL risk. This finding likely resulted because the present population was homogeneous. The operative variables were assessed as risk factors for new or worsened PVL; however, the only variable that reached significance on multivariate analysis was whether the sternum was closed primarily or left open because of hemodynamic instability in the immediate postoperative observation period. In the single ventricle reconstruction trial, infants who were left with an open sternum postoperatively were at increased risk of both mortality and morbidity. ${ }^{31}$ This finding held for both delayed sternal closure owing to hemodynamic instability after surgery and for centers in which the sternum was routinely left open as a 
part of planned postoperative care. The single ventricle reconstruction trial did not evaluate postoperative brain MRI scans; thus, no known previous association with white matter injury could be determined.

Andropoulus and colleagues ${ }^{12}$ reported brain TMS to be the primary risk factor for both pre- and postoperative PVL in a mixed cohort of neonates with complex CHD. In the present study, we did not find TMS to be a significant predictor of new or worsened postoperative injury in our homogeneous cohort. However, patients with single ventricle physiology have, in general, a lower average TMS than neonates with other forms of $\mathrm{CHD}^{12}$ and have the greatest risk of PVL. In the present cohort, we observed a narrow range of TMS. Therefore, the association between TMS and PVL risk could have easily been missed in our study. Other patient characteristics such as sex and HLHS subtype (ie, aortic atresia or aortic stenosis), which have previously been shown to be significant predictors of preoperative PVL, ${ }^{29}$ were not significant predictors of acquired postoperative injury in the present cohort.

The main limitation of the present study was that the preoperative cerebral hemodynamics were only measured on the morning of surgery. Thus, all temporal data on the time to surgery were cross-sectional. To understand the mechanism behind the result that the time to surgery significantly predicted for new or worsened postoperative PVL, longitudinal measures of cerebral hemodynamics from birth until surgery are required. Additionally, we noted that our derivation of optical BFI depends on assumptions about the optical properties of the tissue, primarily its reduced scattering coefficient $\left(\mu_{s}^{\prime}\right)$; the scattering coefficient determination, however, is susceptible to various error sources (eg, flexible probes, imperfect semi-infinite geometry). Recently, Jain and colleagues ${ }^{18}$ demonstrated that the optical BFI and index of $\mathrm{CMRO}_{2}$ correlated better with blood flow and $\mathrm{CMRO}_{2}$ in the sagittal sinus measured from the MRI scans when the reduced scattering coefficient was assumed to be the same for all subjects. ${ }^{18}$ In the present study, we measured $\mu_{s}^{\prime}$ for each subject and used these data in the BFI determination. As a check, we assumed a fixed value for $\mu_{s}^{\prime}$ for all subjects; in that case, our analysis produced a preoperative BFI that was not significantly different between the groups with and without a large postoperative PVL volume. Therefore, additional investigation, including more accurate measures of $\mu_{s}^{\prime}$ and serial measurements of BFI from birth to surgery from individual patients, is crucial for understanding the role of CBF in injury risk.

Additionally, the results we have reported were from a single center; these findings should be confirmed at other centers that treat patients using different operative strategies. However, the high statistical significance of the predictability of new or worsened postoperative PVL stratified by the time to surgery we have reported strongly suggests that decreasing the time to cardiac surgery for neonates with HLHS will decrease the probability of new or worsened postoperative PVL. Because the time to surgery was largely determined by surgeon availability and the day of the week on which the patient had been born, we would suggest that these data provide sufficient justification for modifying the operative scheduling of these otherwise healthy patients with HLHS.

\section{CONCLUSIONS}

We investigated the risk of acquired postoperative PVL in otherwise healthy neonates with HLHS. We observed a large amount of new or worsened postoperative PVL in 18 of the 37 patients $(48.7 \%)$ in our cohort. The risk of injury in this population increased significantly with a longer time to surgical repair. Additionally, a significant correlation was found between the time to surgery and $\mathrm{ScO}_{2}$, suggesting that changes in cerebral oxygen metabolism are occurring between birth and surgical repair and might be at the core of this increased risk of injury. Correcting the native, abnormal vascular anatomy as soon as possible might be the most important factor in mitigating brain injury.

We acknowledge invaluable assistance from Natasha Lavin (respiratory therapist), Justine Wilson (MRI technician), Wesley Baker, Andrew Rouff, the operating room staff from The Children's Hospital of Philadelphia, and, most importantly, the patients and their families.

\section{References}

1. Hoffman JIE, Kaplan S. The incidence of congenital heart disease. J Am Coll Cardiol. 2002;39:1890-900.

2. Graham EM, Zyblewski SC, Phillips JW, Shirali GS, Bradley SM, Forbus GA, et al. Comparison of Norwood shunt types: do the outcomes differ 6 years later? Ann Thorac Surg. 2010;90:31-5.

3. Bellinger D, Wypij D, Rivkin M, DeMaso D, Robertson R, Dunbar-Masterson C, et al. Adolescents with d-transposition of the great arteries corrected with the atrial switch procedure. Pediatr Cardiol. 2011;124:1361-9.

4. Marino B, Lipkin P, Newburger J, Peacock G, Gerdes M, Gaynor J, et al; American Heart Association Congenital Heart Defects Committee, Council on Cardiovascular Disease in the Young, Council on Cardiovascular Nursing, and Stroke Council. Neurodevelopmental outcomes in children with congenital heart disease: evaluation and management: a scientific statement from the American Heart Association. Circulation. 2012;126:1143-72.

5. Shillingford A, Glanzman M, Ittenbach R, Clancy R, Gaynor J, Wernovsky G. Inattention, hyperactivity, and school performance in a population of school age children with complex congenital heart disease. Pediatrics. 2008;121: 759-67.

6. Mahle W, Tavani F, Zimmerman R, Nicolson S, Galli K, Ganor J, et al. An MRI study on neurological injury before and after congenital heart surgery. Circulation. 2002;106:109-14.

7. Imamura T, Ariga H, Kaneko M, Watanabe M, Shibukawa Y, Fukuda Y, et al. Neurodevelopmental outcomes of children with periventricular leukomalacia. Pediatr Neonatol. 2013;54:367-72.

8. Fawer CL, Diebold P, Calame A. Periventricular leucomalacia and neurodevelopmental outcome in preterm infants. Arch Dis Child. 1987;62:30-6.

9. Miller SP, Ferriero DM, Leonard C, Piecuch R, Glidden DV, Partridge C, et al. Early brain injury in premature newborns detected with magnetic resonance imaging is associated with adverse early neurodevelopmental outcome. J Pediatr. 2005; 147:609-16.

10. Bellinger D, Wypij D, du Plessis A, Rappaport L, Riviello J, Jonas R, et al. Devel opmental and neurologic effects of alpha-stat versus $\mathrm{pH}$-stat strategies for deep 
hypothermic cardiopulmonary bypass in infants. J Thorac Cardiovasc Surg. 2001;121:374-83.

11. Gaynor J, Stopp C, Wypij D, Andropoulus D, Atallah J, Beca J, et al; International Cardiac Collaborative on Neurodevelopment Investigators, Pediatric Heart Network Investigators. Abstract 12437: early neurodevelopmental outcomes after cardiac surgery in infancy have not improved: a multi-center retrospective analysis of 1,718 patients. Circulation. 2012;126:A12437.

12. Andropoulus D, Hunter J, Nelson D, Stayer S, Stark A, McKenzie E, et al. Brain immaturity is associated with brain injury before and after neonatal cardiac surgery with high-flow bypass and cerebral oxygenation monitoring. J Thorac Cardiovasc Surg. 2010;139:543-56.

13. Beca J, Gunn J, Coleman L, Hope A, Reed PW, Hunt RW, et al. New white matter injury after infant heart surgery is associated with diagnostic group and use of circulatory arrest. Circulation. 2013;127:917-79.

14. Dent C, Spaeth J, Jones B, Schwartz S, Glausser T, Hallinan B, et al. Brain magnetic resonance imaging abnormalities after the Norwood procedure using regional cerebral perfusion. J Thorac Cardiovasc Surg. 2005;130: 1523-30.

15. Durduran T, Choe R, Baker WB, Yodh AG. Diffuse optics for tissue monitoring and tomography. Rep Prog Phys. 2010;73.

16. Goff DA, Buckley EM, Durduran T, Wang J, Licht DJ. Noninvasive cerebral perfusion imaging in high-risk neonates. Semin Perinatol. 2010;34: 46-56.

17. Buckley EM, Lynch JM, Goff DA, Schwab PJ, Baker WB, Durduran T, et al. Early postoperative changes in cerebral oxygen metabolism following neonatal cardiac surgery: effects of surgical duration. J Thorac Cardiovasc Surg. 2012; 145:196-205.

18. Jain V, Buckley EM, Licht DJ, Lynch JM, Schwab PJ, Naim MY, et al. Cerebral oxygen metabolism in neonates with congenital heart disease quantified by MRI and optics. J Cereb Blood Flow Metab. 2014;34:380-8.

19. Buckley EM, Naim MY, Lynch JM, Goff DA, Schwab PJ, Diaz LK, et al. Sodium bicarbonate causes dose-dependent increases in cerebral blood flow in infants and children with single-ventricle physiology. Pediatr Res. 2013;73:668-73.

20. Lynch JM, Buckley EM, Schwab PJ, Busch DR, Hanna BD, Putt ME, et al. Noninvasive optical quantification of cerebral venous oxygen saturation in humans. Acad Radiol. 2014;21:162-7.
21. Yushkevich P, Piven J, Hazlett H, Smith R, Ho S, Gee J, et al. User-guided 3D active contour segmentation of anatomical structures: significantly improved efficiency and reliability. Neuroimage. 2006;31:1116-28.

22. Childs AM, Ramenghi LA, Cornete L, Tanner SF, Arthur RJ, Martinez D, et al. Cerebral maturation in premature infants: quantitative assessment using MR imaging. AJNR Am J Neuroradiol. 2001;22:1577-82.

23. Licht DJ, Shera DM, Clancy R, Wernovsky G, Montenegro LM, Nicolson SC, et al. Brain maturation is delayed in infants with complex congenital heart defects. J Thorac Cardiovasc Surg. 2009;137:529-36.

24. Durduran T, Zhou C, Buckley EM, Kim MN, Yu G, Choe R, et al. Optical measurement of cerebral hemodynamics and oxygen metabolism in neonates with congenital heart defects. J Biomed Opt. 2010;15:037004.

25. Wyatt JS, Delpy DT, Cope M, Wray S, Reynolds EOR. Quantification of cerebral oxygenation and haemodynamics in sick newborn infants by near infrared spectrophotometry. Lancet. 1986;328:1063-6.

26. Boas DA, Yodh AG. Spatially varying dynamical properties of turbid media probed with diffusing temporal light correlation. J Opt Soc Am A. 1997;14: 192-215.

27. Pine DJ, Weitz DA, Chaikin PM, Herbolzheimer E. Diffusing wave spectroscopy Phys Rev Lett. 1988;60:1134-7.

28. Buckley EM, Cook NM, Durduran T, Kim MN, Zhou C, Choe R, et al. Cerebral hemodynamics in preterm infants during positional intervention measured with diffuse correlation spectroscopy and transcranial Doppler ultrasound. Opt Exp. 2009; $17: 12571-81$.

29. Goff DA, Shera DM, Tang S, Lavin N, Durning SM, Nicolson SC, et al. Risk fac tors for preoperative periventricular leukomalacia in term neonates with hypoplastic left heart syndrome are patient related. J Thorac Cardiovasc Surg. 2014; 147:1312-8.

30. Gutierrez JA, Theodorou AA. Oxygen delivery and oxygen consumption in pediatric critical care. In: Lucking SE, Maffei FA, Tamburro RF, Thomas NJ, eds. Pediatric Critical Care Study Guide: Text and Review. London: SpringerVerlag; 2012:19-38.

31. Tabbutt S, Ghanayem N, Ravishankar C, Sleeper LA, Cooper DS, Frank DU, et al. Risk factors for hospital morbidity and mortality after the Norwood procedure: a report from the Pediatric Heart Network single ventricle reconstruction trial. J Thorac Cardiovasc Surg. 2012;144:882-95.

\title{
EDITORIAL COMMENTARY
}

\section{Should we be doing the Norwood procedure sooner?}

\author{
Richard A. Jonas, MD
}

See related article on pages $2181-8$.

The article by Lynch and colleagues from the University of Pennsylvania and Children's Hospital of Philadelphia in

From the Department of Cardiovascular Surgery, Children's National Medical Center, Washington, DC

Disclosures: Author has nothing to disclose with regard to commercial support.

Received for publication July 1, 2014; accepted for publication July 16, 2014; available ahead of print Aug 20, 2014.

Address for reprints: Richard A. Jonas, MD, Department of Cardiovascular Surgery, Children's National Medical Center, 111 Michigan Ave NW, Washington, DC 20010 (E-mail: rjonas@cnmc.org).

J Thorac Cardiovasc Surg 2014;148:2188-9

$0022-5223 / \$ 36.00$

Copyright (c) 2014 by The American Association for Thoracic Surgery

http://dx.doi.org/10.1016/j.jtcvs.2014.07.016 this issue of the Journal draws the provocative conclusion that the Norwood procedure should not be delayed beyond the first few days after birth. They suggest that there is a greater risk of brain injury when surgery is undertaken at 5 days of age relative to 3 days of age. There are some important limitations to the study, however, that cast doubt on the advisability of applying this recommendation to all patients with hypoplastic left heart syndrome (HLHS) irrespective of clinical status.

The report describes a comprehensive study of 37 neonates who had a Norwood procedure and who underwent preoperative and early postoperative brain magnetic resonance imaging scans. The patients also underwent preoperative and postoperative monitoring of cerebral oxygen saturation and cerebral blood flow with customdesigned optical techniques analogous to near-infrared 